\title{
CALL CENTER OFFSHORE: O CASO OUT BRAZIL
}

\section{Maria Cecilia Coutinho de Arrida}

Escola de Administração de Empresas de São Paulo, Fundação Getulio Vargas

\section{Onófrio Notarnicola Filho}

Escola de Administração de Empresas de São Paulo, Fundação Getulio Vargas

\section{Nádia Vernes Almeida}

Escola de Administração de Empresas de São Paulo, Fundação Getulio Vargas

\section{Introdução}

Gustavo Nogueira acaba de chegar de uma viagem internacional em que viu novas estratégias, tecnologias e usos de centrais de relacionamento, ou call centers. Ainda no aeroporto, enquanto espera a esteira rolar, percebe que o seu raciocínio o faz associar samba, sol e futebol ao fato de que todos falam português. Então percebeu com mais clareza como é forte o peso da responsabilidade que trouxe sobre seus ombros. Não seria muita ousadia? Estaria à altura do que lhe foi proposto? Como Diretor de Negócios Internacionais da Out Brazil, empresa relativamente recente, criada em 1999, não seria insano abrir concorrência com a Índia ou com as Filipinas, entrando nesses mercados reconhecidamente fortes em call centers internacionais? Se a Out Brazil tem boa base tecnológica, por que não? Afinal, empreender significa arriscar.

\section{CFGV-EAESP/RAE 2010}

Todos os direitos reservados. Permitida a citação parcial, desde que identificada a fonte. Proibida a reprodução total. Em caso de dúvidas, consulte a Redação: gvcasos.redacao@fgv.br; (11) 3799-3717 
Atender grandes clientes internacionais, a partir do Brasil? De uma cidade média da Região Sudeste do Brasil? Em inglês? Mas se foram eles que solicitaram uma proposta... O que foi que eles viram em nós? Por que as empresas investiriam no Brasil, em atendimento offshore? Gustavo busca respostas quando recebe uma ligação no celular. É Renata Souza, gerente de marketing e recursos humanos da Out Brazil, que lhe dá as boas-vindas. A executiva fica feliz por saber que há grandes novidades, principalmente porque se referem aos agents, o core da empresa.

Após a conversa com Renata, Gustavo pensa e repensa sobre a proposta de valor que deverá preparar, baseada no seu entendimento para o segmento-alvo de offshore. Sabe de antemão que o mercado mundial já apresenta sinais de fadiga por propostas tradicionais e que são necessários novos atores nesse mercado. Há riscos envolvidos, mas indiscutivelmente poderão advir daí grandes receitas para a sua unidade de negócio, além de um mercado promissor para outras oportunidades para a sua organização global. Mas como? Irá estruturar uma posição competitiva do Brasil versus as competidoras tradicionais como Índia, Canadá, Irlanda e mesmo Argentina e México? Será possível, mesmo com todo o apoio e incentivos do governo federal brasileiro, obter êxito, num setor altamente regulamentado?

O primeiro passo é estruturar um plano estratégico que sirva de suporte ao desenvolvimento sustentável das exportações brasileiras em serviços de call center. Entender a demanda global, formular uma oferta internacional e criar um fórum de discussões com os demais executivos da sua organização foram os principais tópicos questionados mentalmente por Gustavo Nogueira. Entre outras coisas, Gustavo anteviu a necessidade de visitar empresas de grande porte em nível internacional para entender outras possíveis demandas e desafios, a fim de definir os fatores críticos da proposta de valor. Outros elementos diferenciadores - como a proximidade geográfica, afinidade com a cultura norte-americana e fuso horário - deveriam ser valorizados na proposta. 


\section{História da Out Brazil}

Empresa pertencente ao Braziltech, um grande grupo econômico de Minas Gerais, a Out Brazil foi criada no final da década de 1990. Especializada em call/contact centers, oferece serviços e soluções voltadas especialmente para empresas que consideram a central de atendimento uma estratégia fundamental no relacionamento com seus clientes. Alguns desses serviços são: gerenciamento de infraestrutura, service desk, customer care, Serviços de Atendimento aos Clientes (SACs), CRM, televendas, gestão de treinamento, gestão de varejo, offshoring e consultoria em processos, tecnologia da informação (TI) e recursos humanos.

Por volta de 2002, Gustavo Nogueira detectou certa movimentação no setor de call centers. Grandes transnacionais buscavam alternativas de redução de custos, terceirizando seu atendimento a clientes. Na Europa Ocidental, alguns tradicionais centros multilíngues da Irlanda deram lugar a call centers no Leste Europeu e na África. Várias empresas norte-americanas passaram a sede dos seus call centers para outros países, mas especialmente para a Índia e para as Filipinas, pela facilidade do idioma. No entanto, para essas empresas, poderia ser conveniente diversificar o fornecimento a fim de não “deixar todos os ovos em um único cesto". Gustavo Nogueira salientou, para diversos empresários estrangeiros, as vantagens que o Brasil poderia oferecer: mesmo fuso horário, perfil cultural dos atendentes, alto nível de desenvolvimento tecnológico, avançados processos de planejamento estratégico. Não haveria perda de qualidade no atendimento offshore, ainda que o custo de curto prazo não fosse o menor do mercado.

Em 2004, a Out Brazil começou a ser efetivamente considerada uma alternativa. Os primeiros casos de atendimento offshore se concretizaram e a Out Brazil foi ganhando experiência e visibilidade. Várias empresas multinacionais vieram ao Brasil em visitas prospectivas para avaliar aspectos da infraestrutura, processos, tecnologia, disponibilidade de boas escolas de línguas, formação e treinamento para os agents do call center, profissionais que, no Brasil, são conhecidos como “operadores", "atendentes" ou "representantes". 
Em 2007, empresas multinacionais deslocaram seus call centers offshore para a América Latina. Hoje, algumas estão estudando se devem retomar as atividades de call center no próprio país, mesmo que terceirizadas, ou se devem contratar executivos desses call centers para trabalhar nos Estados Unidos, permanecendo os agentes offshore.

A Out Brazil posiciona-se hoje no mercado como uma empresa de outsourcing que oferece soluções completas para seus clientes. Possui três sites de atendimento, sendo dois na cidade de sua sede, num polo econômico de Minas Gerais, e um próximo a São Paulo. Com cerca de 4.000 posições de atendimento, gera mais de 7.000 empregos, entre diretos e indiretos. Suas instalações denotam a cultura ética e de responsabilidade social de seus diretores: prédio horizontal, adaptado para portadores de necessidades especiais e pessoas na terceira idade.

No Brasil, a Out Brazil é uma das pioneiras na prestação de serviços offshoring, prestando atendimento durante 24 horas por dia, sete dias por semana. Em sua carteira de clientes atuais, constam empresas de grande porte, muitas das quais líderes de inúmeros setores da economia, no Brasil, nos Estados Unidos e na Europa.

\section{Quem faz a Out Brazil?}

Gustavo Nogueira completou seu MBA em um importante centro em Minas Gerais e decidiu permanecer na Região Sudeste do Brasil, orientando seus esforços profissionais no sentido de alinhar inovações tecnológicas com as oportunidades de mercado. Desde 1999, acompanhou de perto o rápido desenvolvimento dos SACs, dos call/contact centers e da terceirização de processos. Em 2008, Gustavo passou a ocupar o cargo de vice-presidente de negócios internacionais da Out Brazil. Embora bem-sucedido, Gustavo está sempre buscando novos desafios.

Renata Souza, gerente de marketing e de recursos humanos da Out Brazil, é muito otimista. Seu trabalho intenso e organizado representa forte apoio para Gustavo tomar decisões estratégicas. Conhecendo bem os operadores do call center, Renata vê vantagens competitivas e acredita que a 
empresa continuará se destacando nos cenários nacional e internacional. O perfil dela é importante para a Out Brazil, pois integra duas formações que respondem aos requisitos fundamentais do negócio de serviços: marketing e gestão de pessoas. Fala fluentemente inglês e espanhol, e já está começando a se comunicar em mandarim. Renata percebe que não apenas a tecnologia contribui para a efetivação dos negócios no nível globalizado, mas a necessidade de conhecimento e convívio com vários costumes instituiu uma nova realidade, em que a cultura dos países, a cultura organizacional e a ética surgem no primeiro plano, ao lado de fatores econômicos, tecnológicos e estratégicos, quando se pensa em resultados nesse ramo de negócios. Renata sabe que, dos climas organizacional e ético da empresa, dependerá a qualidade dos atendimentos.

Os agents do call center offshore da Out Brazil, em sua maioria, são brasileiros que moraram nos Estados Unidos e, consequentemente, falam bem o inglês. São responsáveis, no dia a dia, pelos atendimentos ativo e receptivo. Existe uma tranquilidade por parte dos americanos, pois o sotaque dos agents brasileiros não é tão forte quanto o dos hispânicos (espanhol) ou o dos indianos (inglês). Renata Souza comenta que os norte-americanos definem o sotaque brasileiro como engraçadinho, carregado de uma especial simpatia, que aparentemente difere do espanhol e do indiano. Os clientes, normalmente, não conseguem identificar a origem do agent, mas não estranham, pois o americano está bastante acostumado com os imigrantes, o que significa saber lidar com diferentes sotaques, às vezes bem mais acentuados.

Quando começam a trabalhar em televendas com clientes norte-americanos, os agents da Out Brazil às vezes ouvem: "De onde você é?". Quando sabem que são brasileiros, mudam o tom da conversa, perguntam sobre o país e, então, relatam o motivo da chamada. Apreciam as práticas dos agents brasileiros, por estes exercerem suas obrigações de modo solícito, alegre, cordial e gentil.

Em geral, os agents trabalham seis horas por dia. Com freqüência, acumulam mais um emprego, por vezes como professores de inglês. Para manter a fluência e assegurar boa compreensão dos textos ou sites relativos ao trabalho, o inglês é sempre a língua falada na área de call center da Out Brazil. Atividades de supervisão e reuniões de trabalho são sempre conduzidas em inglês. 


\section{O contexto dos telesserviços}

No Brasil, as atividades de call center só adquiriram grande representatividade a partir da década de 1990, como consequência da privatização do setor de telecomunicações, em 1998, do desenvolvimento da informática, do lançamento do Código de Defesa do Consumidor, que protege os negócios feitos por telefone, e das próprias mudanças em costumes culturais.

Até essa época, o local onde se realizavam as operações era conhecido como Central de Telemarketing. A introdução da informática permitiu a mensuração de ligações e a produtividade dos operadores, a unificação de cadastros, além de agregar as diversas ações de marketing.

No período de 2004-2007, o setor de call centers no Brasil cresceu aproximadamente 235\%, tornando-se um dos maiores empregadores do país, principalmente de jovens e mulheres (Quadro 1).

Trata-se de um setor em que $74 \%$ dos empregados possuem o segundo grau e $22 \%$ têm curso superior. Atualmente, mais de 1 milhão de brasileiros trabalham em operações de call/contact center, próprias ou terceirizadas.

Mulheres que saíram do mercado de trabalho e pretendem retornar explicam a expressiva representatividade feminina. Existe um grande percentual de mulheres com mais de 40 anos de idade, que, em geral, possuem uma boa habilidade no trato com o consumidor, característica ideal para exercer ações ativas ou receptivas.

Uma pesquisa da Global Center Industry Project, coordenada no Brasil por professores do Programa de Pós-Graduação em Administração da Pontifícia Universidade Católica de São Paulo (PUC-SP) e pela Associação Brasileira de Telesserviços (ABT), indicou que as vendas em call centers próprios e terceirizados cresceram $64 \%$ em dois anos, propiciando um aumento de $69 \%$ de empregos em 2007. De acordo com o estudo, $72 \%$ dos atendimentos com o consumidor são realizados por $e$-mail, enquanto $67 \%$ se dão via fax. 


\section{Quadro 1}

Alguns dados do setor de call centers no Brasil

\begin{tabular}{|l|}
\hline $\mathbf{6 0 \%}$ dos profissionais que trabalham com telemarketing têm entre 18 e 35 anos; \\
\hline $\mathbf{7 6 , 2 0 \%}$ dos atendentes são mulheres; \\
\hline $\mathbf{4 7 \%}$ dos call centers são próprios e $53 \%$ são tercerizados; \\
\hline $\mathbf{5 0 \%}$ dos call centers têm menos de 100 funcionários; $25,4 \%$ têm mais de 500 e 24,6\% têm menos de $500 ;$ \\
\hline $\mathbf{6 9 \%}$ dos call centers pretendem contratar mais funcionários em 2007. \\
\hline
\end{tabular}

Fonte: Global Center Industry Project, PPG-FEA-PUC-SP, ABT, 2007.

Aspectos tecnológicos e de gestão

A TI revela-se um fator determinante para a exploração do mercado externo. É uma ferramenta interna da organização, que contribui para melhorias contínuas nos processos de tomada de decisão. Auxilia o fluxo operacional e sua produtividade em sistemas integrados de gestão empresarial, como o Enterprise Resource Planning (ERP), o CRM, sistemas de gerenciamento do relacionamento dos clientes com a organização e outros sistemas de apoio à decisão, que visam atender aos diversos níveis de suporte na organização, sejam operacionais, táticos ou estratégicos.

A organização Braziltech, em que a Out Brazil foi inserida desde sua criação, teve como uma das suas principais políticas estratégicas trabalhar como empresa-rede, estimulando a participação do funcionário em suas decisões estratégicas quanto ao rumo da organização do grupo. A empresa desdobra-se em diversas "microempresas internas", como são conhecidas pelo grupo, identificadas pelos seus centros de resultados. Estes são chefiados pelos denominados Coordenadores de Centros de Resultados.

Isso colabora de uma forma bastante objetiva na resolução dos problemas operacionais, e, muitas vezes, com ideias originais, não somente para atividades administrativas como para o uso na automação dos seus processos internos essenciais de negócios e para o uso aplicado da TI, tornando a Out Brazil uma empresa inovadora nesse mercado em grande desenvolvimento. 
Os call centers têm apresentado, em sua história, uma constante evolução, incorporando novas funcionalidades e novos sistemas e formas de comunicação, integrando sistemas simples aos mais complexos. Com o aumento das necessidades e das transferências dos processos de negócios para empresas como a Out Brazil, torna-se fundamental o aumento e uso constante da TI e das telecomunicações. Outras formas de comunicação, além do atendimento telefônico, como gravação de voz, chat, e-mail, fax e outras que virão, atribuíram ao call center múltiplas funções e características de canais de comunicação com toda a cadeia de valor das organizações.

Essas definições parecem suficientes para o entendimento do que é um call center. Sua evolução para o contact center é apresentada em detalhes no relatório do Global Call Center Industry Project (2005). De acordo com esse relatório, nos call centers:

- os empregados trabalham em operações especializadas, que integram tecnologias de sistemas. Essas novas tecnologias complementam a telefonia tradicional, alteram a forma e a multiplicidade de opções nas comunicações com os clientes e fornecedores, transformando os call centers em contact centers. Também é significativo o uso de recursos da internet, como web-enablement, chat, ou outros de telecomunicações;

- os agentes são controlados por sistemas automáticos que virtualmente distribuem o trabalho, controlam o ritmo de atuação e monitoram seus desempenhos;

- os empregados estão em contato direto com os consumidores, por meio de chamadas entrantes, saintes ou uma combinação das duas.

O mercado internacional exige estratégias, funções e processos que levem em consideração fatores ambientais poderosos e interdependentes como a política, a economia, as leis, a tecnologia, a cultura e, sobretudo, a ética nos relacionamentos. No caso de call/contact centers, nem tudo é passível de automação. Os operadores constituem um diferencial competitivo: a sensibilidade, as características culturais integradas à tecnologia, o avanço dos processos e, sem dúvida, o proceder ético pesarão decisivamente diante dos concorrentes, de modo a contribuir para o sucesso dos empreendimentos. 
Para a Out Brazil, os mecanismos para formação da cultura organizacional e a forma como as pessoas se comunicam e conduzem as negociações são essenciais para compreender o modo de operação da empresa.

Nas relações das empresas nacionais com as internacionais, uma das chaves do sucesso reside no processo de aculturação, ou seja, de ajuste e adaptação a uma cultura diferente, em que fatores fundamentais são a comunicação e a linguagem. Numa comunicação por telefone, uma pausa ou um tom de voz pode modificar o significado das palavras que estão sendo pronunciadas, o mesmo podendo-se dizer do silêncio. No caso de call centers, o sotaque, o dialeto e outros padrões de linguagem, falada ou silenciosa, devem ser corretamente compreendidos numa determinada cultura e em um dado segmento de mercado. A diversificação internacional é uma estratégia que não pode ser desvinculada dos aspectos cultural e ético. Ela é essencialmente um conceito de portfolio, utilizado para reduzir riscos e custos, e ocorre em níveis globais ou multinacionais. O sucesso dessa estratégia depende do grau de assimilação da empresa dos valores culturais e da competitividade dos mercados em questão.

Algumas atitudes indicam o clima ético da Out Brazil, no que tange à satisfação dos clientes: honrar compromissos; tratá-los com respeito e integridade. Cultura e ética são essenciais para alcançar um bom entendimento entre operadores e clientes, assegurando sucesso no relacionamento e a consequente contribuição para os resultados da empresa.

\section{Necessidade de programas}

Renata valoriza a importância do clima organizacional, pois o sucesso da Out Brazil se estende a duas empresas: à dos agents e à dos clientes. Se os agents avaliam o seu ambiente de trabalho como positivo, atuam de maneira pró-ativa, e sua relação com os clientes é beneficiada. 
Um dos desafios de Renata é conceber uma proposta, para apresentar à Diretoria da Out Brazil, que contenha pontos fundamentais para a elaboração de um programa de desenvolvimento dos agents, preparando-os para a nova realidade.

Ela pensa em colocar como enfoque principal a tecnologia e a cultura, desenvolvendo, para isso, atividades internas e externas à empresa. Uma ação é desenvolver um ambiente em que os agents percebam aspectos relacionados às suas tarefas, independentemente dos manuais ou dados disponibilizados pela Out Brazil. Por exemplo, os agents poderiam encontrar na intranet novas matérias de importância para um conhecimento mais amplo do produto da empresa-cliente. Outro ponto que Renata busca é ampliar a sensibilidade dos agents em termos de cultura geral. Sabendo mais sobre o que ocorre no mundo, eles estarão sensíveis a assuntos que podem indiretamente colaborar para um melhor atendimento de seus clientes.

\section{Desafios da Out Brazil}

Para Gustavo Nogueira, um dos principais desafios que surgiram nos últimos anos foi justamente compreender e traduzir para o ambiente de negócios os valores percebidos pelo mercado offshore, em função da cultura, da ética e do avançado uso da tecnologia da informação, como vantagens competitivas para o Brasil.

Em serviços de offshoring, muitos são os desafios a serem enfrentados pelas empresas no Brasil: domínio da língua inglesa, maior nível de escolaridade, criação de cultura específica de serviços, uso de tecnologia adequada. O lado vantajoso é que os brasileiros são vistos com simpatia, pois apresentam flexibilidade, vontade de servir e paciência na hora de se comunicar com pessoas de outros países. Ademais, o Brasil apresenta fatores que podem lhe dar vantagens competitivas, a saber: pouca suscetibilidade a desastres naturais, bom serviço dos atendentes, economia estável, com preços semelhantes aos preços internacionais, um mercado interno forte e grande população; fuso horário próximo ao dos Estados Unidos. 
Depois de muito analisar, Gustavo continua com o desafio de decidir qual a melhor estratégia para a Out Brazil. Remete-se às suas aulas de Estratégia Empresarial. Refletindo sobre o caso, quais fatores são fundamentais para que o Brasil apresente vantagem competitiva em relação a países concorrentes, fornecedores do mesmo tipo de serviços? De que maneira a Out Brazil poderá trabalhar os valores culturais e os fatores tecnológicos dentro de padrões éticos? 